\title{
Effects of a convenient silica-coating treatment on shear bond strengths of porcelain veneers on zirconia-based ceramics
}

\author{
Takuya OGURI, Yukimichi TAMAKI, Yasuhiro HOTTA and Takashi MIYAZAKI \\ Department of Oral Biomaterials \& Technology, Showa University School of Dentistry, 1-5-8 Hatanodai, Shinagawa-ku, Tokyo 142-8555, Japan \\ Corresponding author, Yukimichi TAMAKI; E-mail: tamaki@dent.showa-u.ac.jp
}

\begin{abstract}
Porcelain veneering of zirconia is necessary, but chipping of the veneer may cause clinical problems. We investigated the effects of silica coating to improve the bond strength between porcelain veneers and zirconia-based ceramics. The ceramics tested were zirconia/ alumina nanocomposites stabilized with ceria. Three surface treatments, grinding with a carborundum point (CA), sandblasting with alumina (SB), and Silano-Pen treatment (SP), were performed. Untreated specimens (NT) were examined as a control. The surface roughnesses and contact angles after treatment were measured. Shear bond tests were conducted, and the average strengths were calculated. EPMA was used for elemental identifications and surface observations. The bond strengths with SP were $20.00 \pm 3.43 \mathrm{MPa}$ and were significantly larger than that $(15.35 \pm 3.12 \mathrm{MPa})$ of NT $(p<0.05)$. However, differences among treated specimens were not significant. Moreover, SP gave superior wettability, and smoothness as good as NT. These data suggest that SP affects the bond strength between zirconia and a porcelain veneer.
\end{abstract}

Keywords: Zirconia-based ceramics, Shear bond strength, Surface texture, Silica coating, Porcelain veneer

\section{INTRODUCTION}

Significant progress has been achieved in ceramics since the late $1990 \mathrm{~s}^{1-4)}$. In particular, new technological innovations such as heat-pressed ${ }^{5,6)}$, injection-molded ${ }^{7}$, slip-cast ${ }^{8)}$, and glass-infiltrated ceramics ${ }^{9-11}$ have widened the use of ceramics in prosthetic and operative dentistry. However, properties such as brittleness limit their use in applications such as fixed partial dentures.

Since the beginning of the 21st century, zirconium dioxide $\left(\mathrm{ZrO}_{2}\right.$ : zirconia), a new and tough ceramic material, has been receiving increasing attention in dentistry ${ }^{12-16)}$. Initially, its use was restricted to metalfree fixed partial anterior dentures, but its use is being extended to a variety of applications, such as fixed partial posterior dentures, orthodontic brackets ${ }^{19)}$ and dental implant abutment or fixture ${ }^{20,21)}$, as well as simple dental restoration or prostheses ${ }^{17,18)}$. Above all, frameworks using zirconia-based ceramics have gained popularity for use as metal-free, long-lasting, and extensive fixed dental prostheses.

Zirconia-based ceramics are characterized by a tetragonal phase, a monoclinic phase, and a cubic phase, and these phases are mutually interchangeable under some kinds of stress such as heating, sandblasting, and mechanical grinding. It is also well known that volume changes occur when going from monoclinic to tetragonal crystals under the specific actions mentioned above $^{22,23)}$. This phase change is useful for controlling crack propagation in zirconia-based ceramics and contributes to their high fracture toughness. Formation of the tetragonal phase strongly stabilizes zirconia-based ceramics, but other crystal phases are undesirable. To

Color figures can be viewed in the online issue, which is available at J-STAGE.

Received Feb 1, 2012: Accepted Jun 6, 2012

doi:10.4012/dmj.2012-037 JOI JST.JSTAGE/dmj/2012-037 maintain the tetragonal phase at room temperature, zirconia-based ceramics must be stabilized by adding oxides. Yttria is a popular stabilizing additive, giving Y-TZP ${ }^{12,13,16)}$. This new ceramic is useful as a prosthetic frame material because of its high fracture toughness and its precision fabrication with dental CAD/CAM systems. A final prosthetic process is needed to deposit a porcelain veneer on zirconia-based ceramics; however, chipping of the porcelain veneer causes clinical problems. Hydrothermal degradation of the veneer with lowtemperature aging is also controversial ${ }^{16,24)}$. To overcome these problems, some modification techniques have been proposed.

The latest zirconia-based ceramics materials, stabilized by ceria, were developed to achieve better mechanical properties than those of Y-TZP ${ }^{25-28}$. Ceriastabilized tetragonal zirconia/alumina nanocomposites (zirconia nanocomposites) are significantly reinforced by dispersing different nanosized particles into each crystal grain. Furthermore, preparation, prior to veneering, of frameworks as thin as those of traditional porcelainfused metal (PFM) is possible because of the flexibility of these nanocomposites, so extremely light frames of thickness $0.3 \mathrm{~mm}$ can be obtained.

In esthetic restoration, dental PFM has served the profession well for nearly a half-century, but there are many disadvantages to using metals, such as allergic reactions as a result of the release of harmful ions into the body and/or low durability. Most dentists prefer allceramic restoration to traditional PFM methods when attempting to achieve the optimum esthetic results. Generally speaking, fixed-type all-ceramic prostheses usually give better esthetic results than PFM because of the difficulty in blocking out the color and opacity of the metal substructure. Moreover, it has been reported that 
the marginal regions of ceramics are compatible with gingival tissues ${ }^{29)}$.

Porcelain veneering of zirconia-based ceramics is necessary because of their opaque white color and hardness. Much research has already been done on porcelain fused to zirconia ${ }^{30-35)}$. Various surface modification techniques have been recommended, such as sandblasting with different particle sizes and different oxides $^{30,31,34,35)}$, mechanical grinding ${ }^{35)}$, application of hydrogen fluoride ${ }^{34)}$, and heat-treatment ${ }^{30)}$. One report suggested that coarse surfaces contribute to increased bond strength ${ }^{35)}$, but other reports asserted that no significant effect was found ${ }^{30,31)}$. In the case of zirconiabased ceramics, there have been few reports on the effects of surface modification. Most techniques can certainly damage the outer surfaces of zirconia-based ceramics $^{30,31,34,35)}$, and may spoil extremely thin frames. Consequently, an additional surface modification, such as a coating, is expected to be reasonable and to effectively increase the bond strengths between zirconiabased ceramics and porcelain veneers.

Recently, a convenient silica-coating procedure, using a silane-coupling agent, has been developed in Europe and used to improve the bond strength between a metal and a resin composite for crowns ${ }^{36-38)}$. This method involves kinetic spraying, and surface modification is carried out by thermal spraying with liquefied petroleum gas containing a fine silica powder. No disadvantageous morphological changes occur during the preparation because the silicate layer is formed on the surface using a flame. We assume that this method is appropriate for joining dental porcelain to zirconia-based ceramics because silicon is the key element in dental porcelain. The purpose of this study is to investigate the effects of a silica-coating layer for the bond strength between porcelain veneers and zirconia-based ceramics.

\section{MATERIALS AND METHODS}

\section{Specimen preparation}

A ceria-stabilized tetragonal zirconia/alumina nanocomposite (P-NANO ZR (NZR), Panasonic Healthcare, Osaka, Japan) and a dental porcelain veneer (Cerabien ZR (CZR), Noritake Dental Supply Co.,Ltd., Nagoya, Japan) for zirconia-based ceramics were selected for this study. The zirconia-based ceramics and veneering porcelain tested are listed in Table 1. Forty zirconiabased ceramic specimens of dimensions $11 \times 11 \times 2 \mathrm{~mm}^{3}$ were separated using a grinding machine (F-524HDP, Nicco Co., Ltd., Niigata, Japan) with an exclusive cutter (SDC170, Nicco Co., Ltd., Niigata, Japan) from fullsintered zirconia bar (diameter: $12 \mathrm{~mm}$, length: $76 \mathrm{~mm}$ ) for the shear bond tests. Each specimen was finally polished by another grinding device (F-515HDIIP, Nicco Co., Ltd., Niigata, Japan) using two kinds of whetstone (\#325,\#1,000). These specimens were classified into four groups, according to the different surface treatments.

Details of the surface treatments are as follows. The CA specimens were zirconia-based ceramic specimens ground vertically and horizontally for $10 \mathrm{~s}$ with a carborundum point (HARD HP 13, Shofu Inc., Kyoto, Japan) using a commercial rotation device (Lab Master,

Table 1 Materials used in this study

\begin{tabular}{|c|c|c|c|}
\hline Material & Brand & Lot number & Manufacturer \\
\hline $\mathrm{ZrO}_{2}$ & P-NANO ZR (NZR) & & Panasonic Healthcare Co., Ltd. \\
\hline Porcelain & $\begin{array}{c}\text { Cerabien ZR (CZR) } \\
\text { Powder: A2B } \\
\text { SB A3 } \\
\text { Liquid: Forming liquid }\end{array}$ & $\begin{array}{c}16866 \\
19808 \\
\text { BRMVN }\end{array}$ & Noritake Dental Supply Co., Ltd. \\
\hline
\end{tabular}

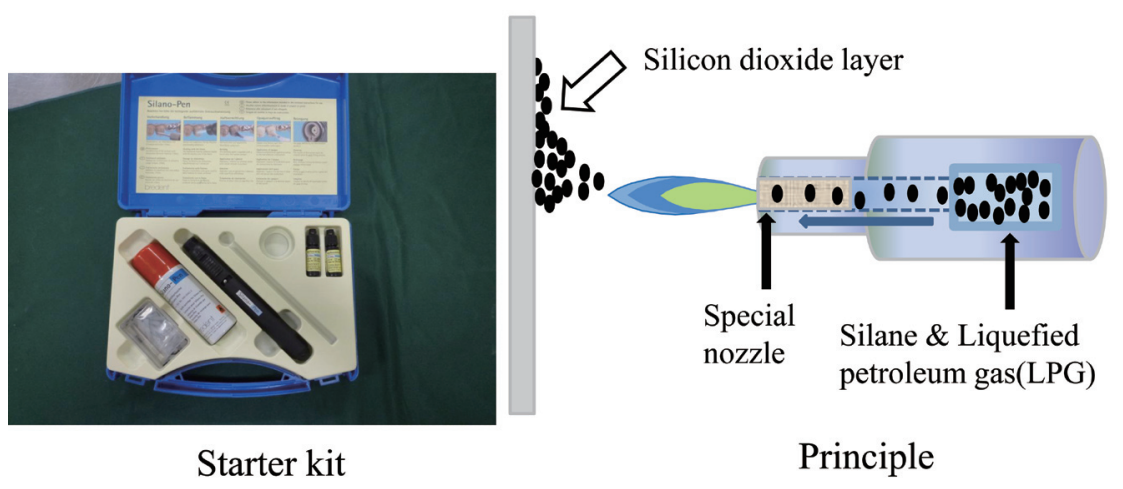

Fig. 1 Schema of Silano-Pen treatment tested in this study. 
Yoshida Co., Ltd., Tokyo, Japan). The SB specimens were sandblasted for $10 \mathrm{~s}$ at an air pressure of $0.2 \mathrm{MPa}$ with alumina particles of average particle size $50 \mu \mathrm{m}$, using a commercial sandblasting apparatus. The distance between the nozzle and the surface was set at $10 \mathrm{~mm}$. The SP specimens were coated for $10 \mathrm{~s}$ using a frame-coating device (Silano-Pen, Bredent GmbH \& Co. KG, Senden, Germany); the Silano-Pen and coating mechanism are shown in Fig. 1. The principle is approximately equal with previous Silicoater treatment ${ }^{39)}$. A silicate layer is quickly formed by spraying with fused silicon dioxide. Untreated specimens, coded NT, were used as a control. All the specimens modified using each treatment was ultrasonically rinsed by an ultrasonic cleaner (US cleaner USD 1R, AsOne Co.,Ltd, Osaka, Japan) with acetone for $3 \mathrm{~min}$, except in the case of SP processing.

\section{Surface roughness}

The surface roughness values $(R a)$ of the zirconiabased ceramic specimens for each modified surface were evaluated using a surface-texture and contourmeasuring instrument (Surfcom 480A, Tokyoseimitsu Co., Ltd., Tokyo, Japan). The cut-off value for the surface roughness was set at $0.8 \mathrm{~mm}$, and the traversing length of the stylus with tip radius of $2 \mu \mathrm{m}$ was $4 \mathrm{~mm}$. The measurements were performed at five different points, and the average values were calculated.

\section{Contact angle measurements}

Prior to the process of building up porcelain on the zirconia-based ceramics, the wettability of each modified surface was investigated by measuring the contact angle using a contact-angle meter (SImage Mini, Excimer Inc., Yokohama, Japan). Deionized water (5 $\mu \mathrm{L}$ ) was dropped onto the center of the specimen using an attached injector. In consideration of energy change with time dependency, each image was taken and recorded $10 \mathrm{~s}$ after injection of a drop onto the specimen. The contact angles were gauged from the captured images using goniometry software, and were provided as average values with their standard deviations. The measurements were repeated three times for each specimen.

\section{Surface topography analyses}

To evaluate the surface topography, specimens modified using each treatment were sputter-coated with gold using an ion-sputtering device (Ion Coater, Eikoseiki Co., Ltd., Tokyo, Japan).

After completing the surface treatments and shear bond tests, elemental analyses for zirconium, aluminum, and yttrium were performed using an electron-probe microanalyzer (EPMA1610, Shimadzu Co., Ltd., Kyoto, Japan). Silicon was also determined for the SP-treated specimens. The experimental conditions were as follows: voltage $20 \mathrm{kV}$, specimen current $50 \mathrm{nA}$, scanning step interval $1 \mu \mathrm{m}$. Simultaneously, the surface texture of the area being analyzed was observed to check the morphology of the specimen from secondary electron (SE) images.

\section{Shear bond tests}

To evaluate the shear bond strengths, a metal cylinder (6 $\mathrm{mm}$ height, $12.0 \mathrm{~mm}$ diameter) with a hollow $(6 \mathrm{~mm}$ diameter) was centered on the each specimen. The shade base powder of CZR was kneaded with attached liner liquid and built up to a thickness of $1 \mathrm{~mm}$ by using a ultrasonic condenser (CeraconII, Shofu Inc., Kyoto, Japan) on zirconia-based specimens modified by each of the treatments mentioned above, and fired in an automatic furnace (KDF Master Spirit, Yoshida Co., Ltd., Tokyo, Japan). The height of initial layer after firing was adjusted to $0.5 \mathrm{~mm}$ by grinding with rotary tools. A thickness of ceramic layer was checked by a caliper (ABS Digimatic Caliper, Mitutoyo Corp., Kawasaki, Japan). A second layer, up to a thickness of $5 \mathrm{~mm}$, was similarly constructed. The heating conditions are shown in Table 2. Each specimen was embedded in an acrylic tube mold using methyl methacrylate resin (Unifast Trad, GC Co., Ltd., Tokyo, Japan) and subjected to bonding tests. The detailed procedure is shown in Fig. 2.

Shear bond tests were performed using a universal testing machine (Instron MD1125, Instron Japan, Kawasaki, Japan) with a $2-\mathrm{kN}$ load cell at a crosshead speed of $1 \mathrm{~mm} / \mathrm{min}$, until separation of the veneer from the zirconia-based ceramic occurred. A force was applied to the specimen so that the shear load was exerted adjacent to and directly to the bonding interface. The

Table 2 Surface treatments for CZR

\begin{tabular}{cc}
\hline Code & Each procedure \\
\hline CA & Mechanical grinding with a carborundum point \\
& for $10 \mathrm{~s}$ \\
SB & Sandblasting with alumina particle $(50 \mu \mathrm{m})$ \\
for $10 \mathrm{~s}$
\end{tabular}

Table 3 Heating condition for CZR

\begin{tabular}{lcc}
\multicolumn{1}{c}{ Heating schedule } & Shade Base & Dentin \\
\hline $\begin{array}{l}\text { Standby temp. } \\
\text { (Vacuum strating) }\end{array}$ & $600\left({ }^{\circ} \mathrm{C}\right)$ & $600\left({ }^{\circ} \mathrm{C}\right)$ \\
Drying time & $5(\mathrm{~min})$ & $7-10(\mathrm{~min})$ \\
Heating rate & $45\left({ }^{\circ} \mathrm{C} / \mathrm{min}\right)$ & $45\left({ }^{\circ} \mathrm{C} / \mathrm{min}\right)$ \\
Maximum firing temp. & $930\left({ }^{\circ} \mathrm{C}\right)$ & $930-940\left({ }^{\circ} \mathrm{C}\right)$ \\
Holding time & $1(\mathrm{~min})$ & $1(\mathrm{~min})$ \\
Vacuum cancelling temp. & $930\left({ }^{\circ} \mathrm{C}\right)$ & $930-940\left({ }^{\circ} \mathrm{C}\right)$ \\
\hline
\end{tabular}




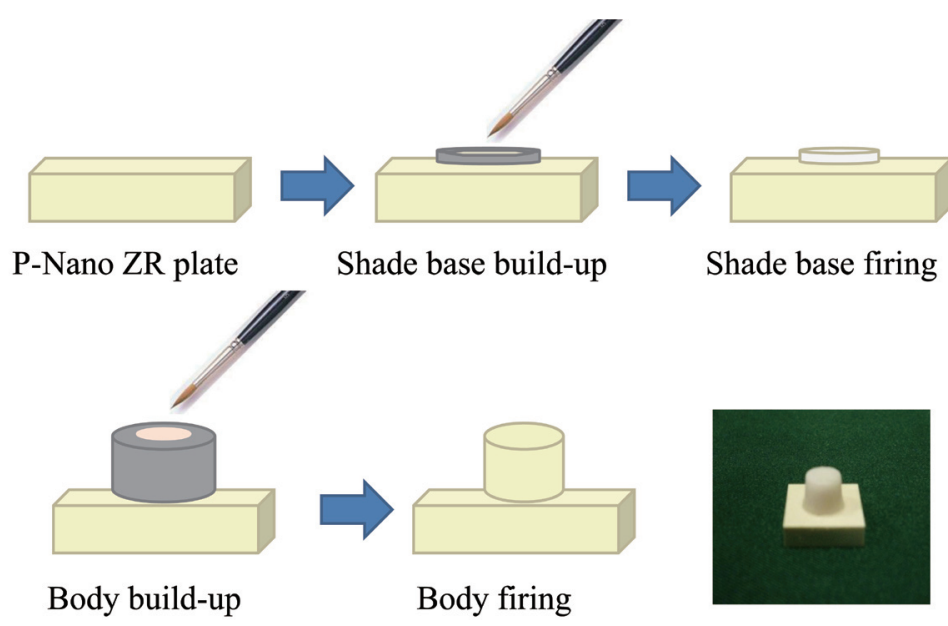

Fig. 2 Specimen fabrication for shear bond tests.

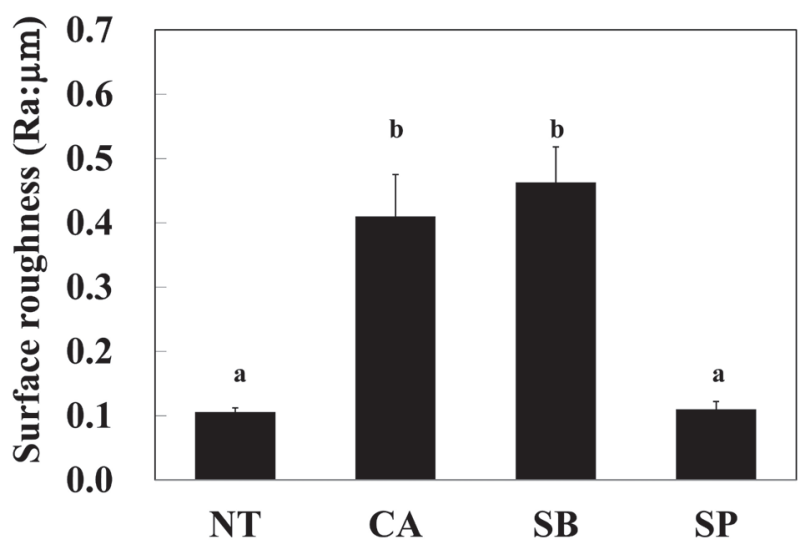

Fig. 3 Surface roughness after each surface treatment. Vertical bars indicate the standard deviation and identical letters indicate that the values are not significantly different $(p>0.05)$.

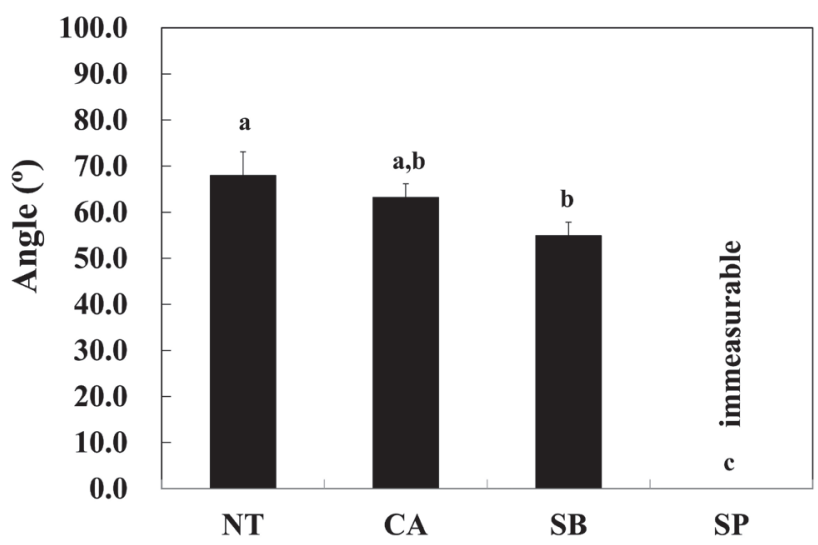

Fig. 4 Contact angle after each surface treatment. Vertical bars indicate the standard deviation and identical letters indicate that the values are not significantly different $(p>0.05)$.

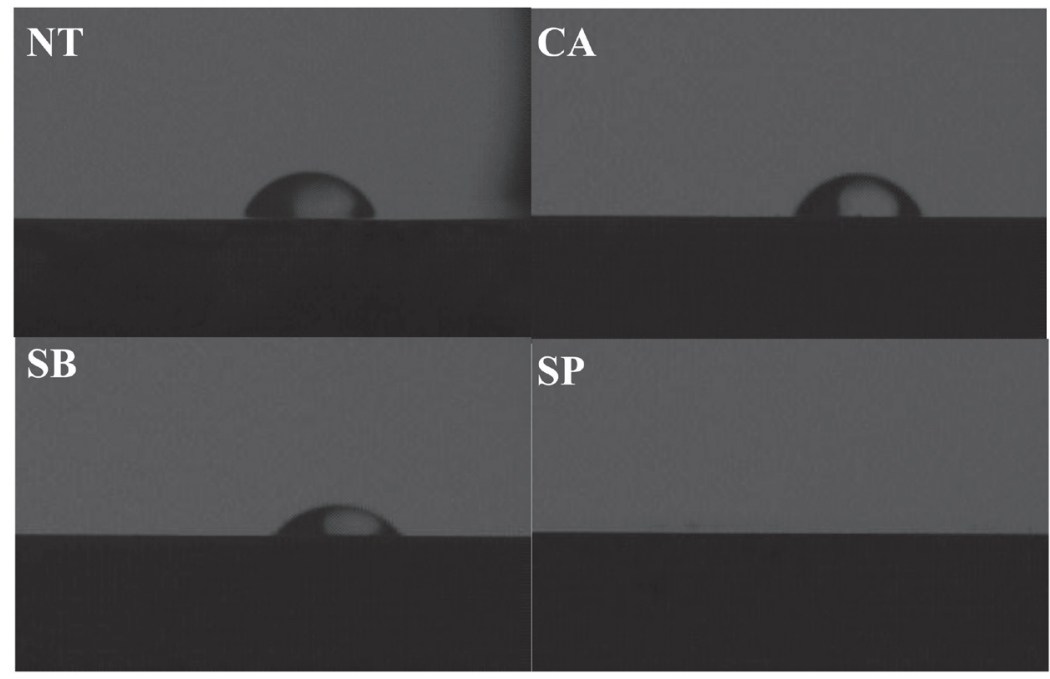

Fig. 5 Typical images of wettability for each treatment. 
shear bond strength was calculated as an average value from 10 data.

\section{Statistical analyses}

Statistical assessments were carried out using one-way analysis of variance. Subsequently, Tukey's HSD multiple comparison was applied to each of the parameters to compare the different surface treatments. Each test was estimated at a level of significance of 0.05 .

\section{RESULTS}

A surface-roughness comparison is shown in Fig. 3.
The data were clearly divided into two significantly different types. One is an uneven surface, produced by $\mathrm{SB}$ and $\mathrm{CA}$, and these $R$ a values were $0.46 \pm 0.06 \mu \mathrm{m}$ and $0.41 \pm 0.07 \mu \mathrm{m}$, respectively. In contrast, the value for SP was $0.11 \pm 0.02 \mu \mathrm{m}$ and then was close to that for NT, which was $0.09 \pm 0.02 \mu \mathrm{m}$; the difference between them was not significant $(p>0.05)$.

The contact-angle measurements are shown in Figs. 4 and 5 . A noteworthy property is the excellent wettability of the SP specimen, which could not be measured and was far superior to those of the other specimens. The contact angle of the CA and NT specimens were the same as each other, and were larger than that of the SB

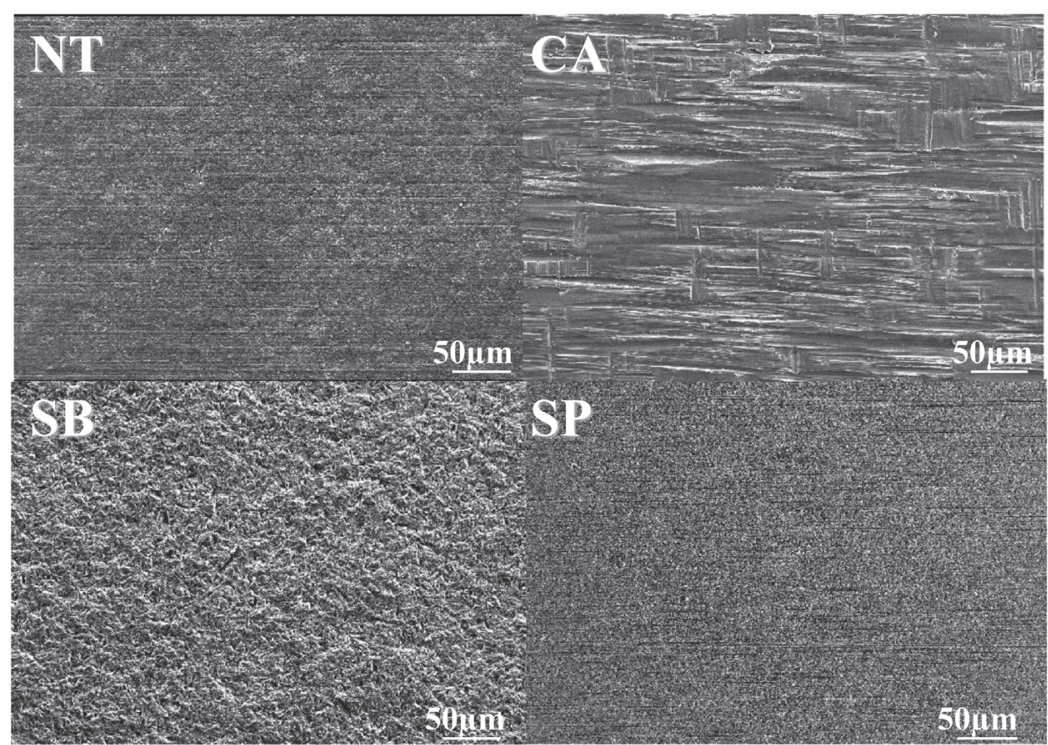

(a)

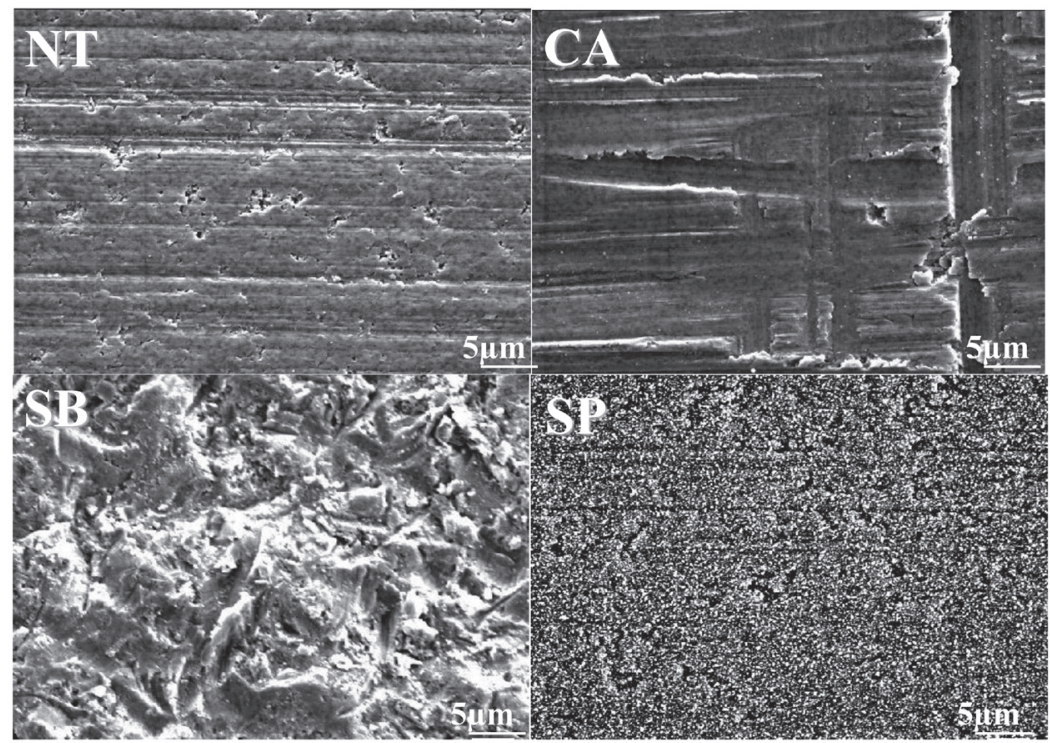

(b)

Fig. 6 (a) Low-magnification $(\times 500)$ SE images after each surface treatment. (b) High-magnification $(\times 5000)$ SE images after each surface treatment. 


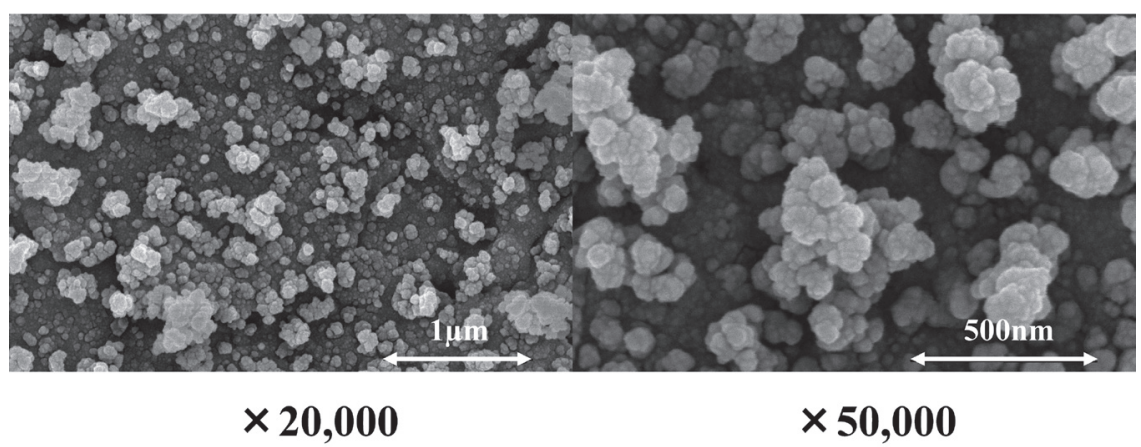

Fig. 7 High-magnification SE images.

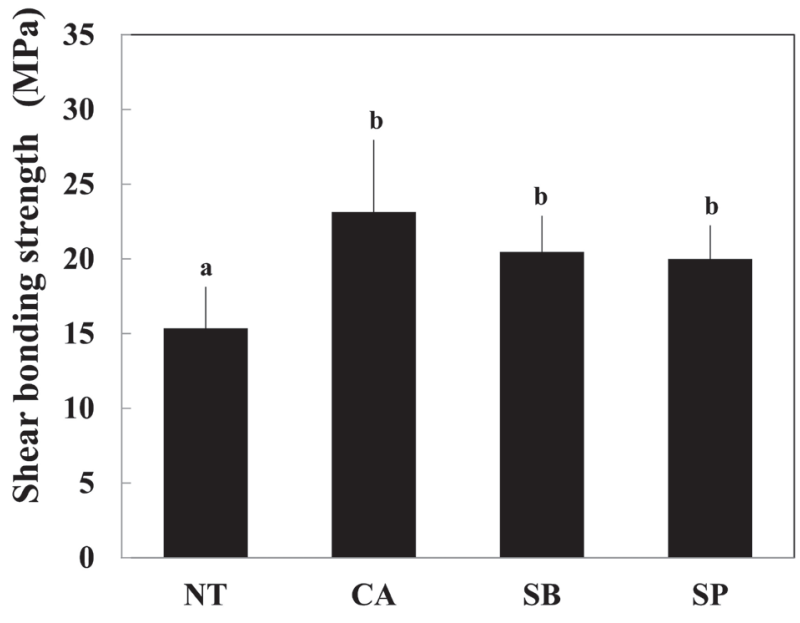

Fig. 8 Shear bond strength for each specimen.

Vertical bars indicate the standard deviation and identical letters indicate that the values are not significantly different $(p>0.05)$.

specimen.

Representative SE images of each specimen are shown in Figs. 6a and 6b. In the low-magnification photographs, there is no apparent difference between SP and NT; however, specific differences between their surface qualities were observed in high-magnification photographs. The SB and CA specimens had distinctive and uneven surface scraped by abrasive technology. They were observed with the low magnification clearly.

Elemental distribution results for each group are presented in Table 3. Basically, there were no large discrepancies among NT, CA, SB, and SP. According to former reports ${ }^{25-28)}$, ceria-stabilized tetragonal zirconia/ alumina nanocomposites consist of three elements, namely zirconium (Zr), aluminum ( $\mathrm{Al})$, and yttrium $(\mathrm{Y})$. Silicon (Si) was not detected in specimens which did not undergo SP treatment. High magnification SE images of specimens after SP treatment are shown in Fig. 7. The images indicate that many nanosized fine grains were scattered and piled up, forming a stratified structure.
Figure 8 shows the results of shear bond strength tests. The highest strength was 23.14 $\pm 5.39 \mathrm{MPa}$, obtained for CA, and those of the others decreased in the order SB $(20.46 \pm 2.79 \mathrm{MPa})>\mathrm{SP}(20.00 \pm 3.43 \mathrm{MPa})>\mathrm{NT}$ $(15.35 \pm 3.12 \mathrm{MPa})$. The value for NT was significantly lower $(p<0.05)$ than those for the other groups; CA $(p=0.001)$, SB $(p=0.017)$, and SP $(p=0.041)$. In addition, there were no significant differences among treatment groups.

SE images of the specimens after the shear bond tests are shown in Fig. 9. The surfaces of the SB, CA, and SP specimens are completely covered by veneering materials. Based on the images shown in Fig. 6a, it was surmised that this surface-covering layer would be a residual substance from the porcelain veneer. In contrast, some scratches seen on the original surface shown in NT of Fig. 6b were clearly exposed in the NT specimen of Fig. 9.

Figure 10 compares NT with SP using mapping analysis for $\mathrm{Zr}, \mathrm{Al}$, and $\mathrm{Si}$. The failure type for NT should be mixed fracture because $\mathrm{Zr}$ is predominant. On the other hand, it was concluded that the SP treatment led to cohesive failure since little $\mathrm{Zr}$ was detected on the surface.

\section{DISCUSSION}

Methods such as shear bond tests ${ }^{30-35)}$, bending tests ${ }^{38)}$, and tensile tests with push-out test ${ }^{39)}$ are used to estimate bond strength. In this study, shear bond tests were chosen due to not only many reports ${ }^{30-35)}$ in the same experimental category but severe testing method. The specimens after grinding or sandblasting had large surface roughness values and shear bond strengths compared with those of the control, and had large. Fischer et al. reported ${ }^{31)}$ that the bonding strength of dental porcelain to zirconia-based ceramics did not depend on the surface roughness, but was affected by the application of opacity ${ }^{31)}$. In contrast, our data suggested that a high surface roughness successfully improved the bonding strength. Shear bond strength values obtained in this study do not have a major difference in comparison with other similar reports ${ }^{30,31}$, and thus the validity of our experiments has been proven indirectly. 


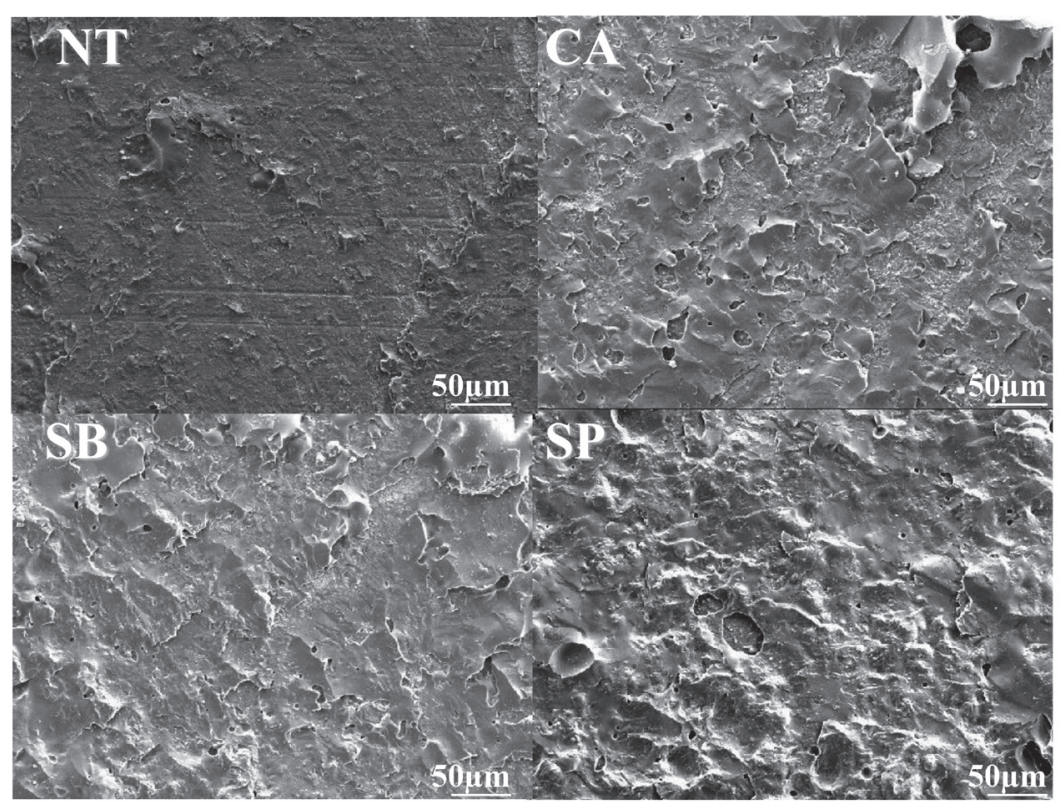

Fig. 9 SE images of specimen surfaces after shear bond tests.

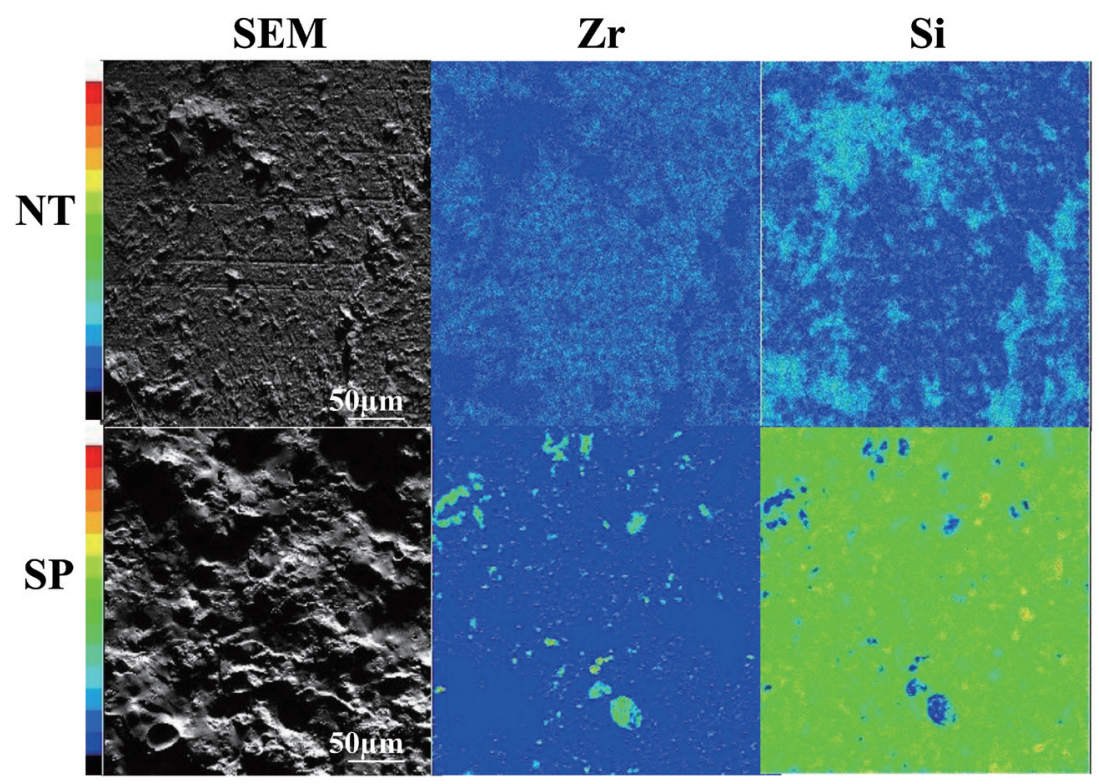

Fig. 10 Element mapping for NT and SP surfaces after shear bond tests.

The shear bond strength is also improved by SP processing, although the average surface roughness value of SP treatment was $0.11 \pm 0.01 \mu \mathrm{m}$ and almost equal to that of the control. This suggests that the surface roughness of zirconia-based ceramics before fusing to porcelain may not be of great significance. Therefore, it was also found that surface coarseness of zirconiabased ceramics may not be a factor of the shear strength improvement. The contact angles were then measured to explore the superiority of SP processing.

When the surface energy of the parent material is large, the wettability is excellent. Because the SP process directly fixes a silane layer composed of fine silicon grains by flaming with gas, it is expected that the target surface will be temporarily activated. In fact, the existence of innumerable nanosized protrusions was clearly observed in the SE images in Fig. 7. The contact angle therefore was small, and favored extension with dental porcelain powder mixed with distilled water. The contact angle on the SP processed surface was undetectable. Chemical coupling to the dental porcelain is also expected because of silica layer formed on the zirconia-based ceramics 
treated by SP, as shown in Fig. 10 and an electron probe microanalyzer of Table 3. The zirconia-based ceramics modified by SP therefore had a more compatible surface than those produced by the other procedures, and the surface was considered to be advantageous for fusing to porcelain because it was unnecessary for a thin frame to be exposed to mechanical forces such as blasting or grinding, intentionally.

This prediction is supported by the results of surface observation performed after the shear bond tests, shown in Fig. 10. Cutting lines traced when making the specimens were clearly observed on the NP surface after shear bond examination; however, it was not found in other specimens. This proves that there is partial adhesive failure in the NT specimen. In contrast, the specimens treated by SP processing were almost as smooth as the NT specimens, and were entirely covered by the porcelain veneer after the bonding tests. It was therefore considered that the SP treatment conducted cohesive failure. These results suggest that SP treatment is simple and safe enough for use on zirconiabased ceramics to be fused with dental porcelain, since SP treatment gives excellent wettablity and new layer formation coated by silica on the surface.

In this study, preparation of the specimens for the shear bond tests started about $1 \mathrm{~h}$ after rinsing in acetone solution was performed. Additionally, the ultrasonic rinsing process was omitted in the SP treatment because it was still uncertain whether the silica layer produced by SP strongly adhered to the surface. Moreover, it was thought that the surface energy would decrease with time, and treatment effects would fade. Detailed mechanism for increasing the bond strength between veneering porcelain and NZR is also indefinite. Furthermore, fatigue test with repetitive loading and the heat stress like thermocycling that simulated a clinic situation are not carried out. Consequently, we will be performing further examinations in the near future to clarify these points.

Within this limited study, we concluded that SP treatment was possible to increase the bond strength between veneering porcelain and zirconia-based ceramics without damaging zirconia surface.

\section{ACKNOWLEDGMENTS}

The authors would like to thank Panasonic Healthcare Co., Ltd., for providing the zirconia-based ceramics tested in these experiments, and for their advice.

\section{REFERENCES}

1) Denry I L. Recent advances in ceramics for dentistry. Crit Rev Oral Biol Ued 1996; 7: 134-143.

2) Piconi C, Maccauro G. Zirconia as a ceramic biomaterial. Biomaterials 1999; 20: 1-25.

3) Tinscherta J, Zwez D, Marx R, Anusavice KJ. Structural reliability of alumina-, feldspar-, leucite-, mica- and zirconiabased ceramics. J Dent 2000; 28: 529-535.

4) Raigrodski AJ. Contemporary materials and technologies for all-ceramic fixed partial dentures: A review of the literature.
J Prosthet Dent 2004; 92: 557-562.

5) Gormana CM, McDevitta WE, Hillb RG. Comparison of two heat-pressed all-ceramic dental materials. Dent Mater 2000; 16: 389-395.

6) Gemalmaz DG. Use of heat-pressed, leucite-reinforced ceramic on anterior and posterior onlays: A clinical report. J Prosthet Dent 2002; 87: 133-135.

7) Quinna JB, Quinnb GB, Kelly JR, Scherrer SS. Fractographic analyses of three ceramic whole crown restoration failures. Dent Mater 2005; 21: 920-929.

8) Bindl A, Mormann WH. Marginal and internal fit of allceramic CAD/CAM crown copings on chamfer preparations. J Oral Rehab 2005; 32: 441-447.

9) Guazzato M, Albakry M, Quach L, Swain MV. Influence of surface and heat treatments on the flexural strength of a glass-infiltrated alumina/zirconia-reinforced dental ceramic. Dent Mater 2005; 21: 454-463.

10) Lawn BR, Deng Y, Lloyd IK, Janal MN, Rekow ED, Thompson VP. Materials design of ceramic-based layer structures for crowns. J Dent Res 2002; 81: 433-438.

11) Jung YG, Peterson IM, Pajares A, Lawn BR. Contact damage resistance and strength degradation of glass-infiltrated alumina and spinel ceramics. J Dent Res 1999; 77: 804-814.

12) Luthardt RG, Holzhüter MS, Sandkuhl O, Herold V, Schnapp JD, Kuhlisch E, Walter M. Reliability and properties of ground Y-TZP-zirconia ceramics. J Dent Res 2002; 81: 487491.

13) Luthardta RG, Holzhüter MS, Rudolpha H, Heroldb V, Waltera MH. CAD/CAM-machining effects on Y-TZP zirconia. Dent Mater 2004; 20: 655-662.

14) Christensen GJ. Choosing an all-ceramic restorative material Porcelain-fused-to-metal or zirconia-based? JADA 2007; 138: 662-665.

15) Komine F, Iwai T, Kobayashi K, Matsumura H. Marginal and internal adaptation of zirconium dioxide ceramic copings and crowns with different finish line designs. Dent Mater J 2007; 26: 659-664.

16) Kim HT, Han JS, Yang JH, Lee JB, Kim SH. The effect of low temperature aging on the mechanical property \& phase stability of Y-TZP ceramics. J Adv Prosthodont 2009; 1: 113117.

17) Fischer H, Weber M, Marx R. Lifetime prediction of allceramic bridges by computational methods. J Dent Res 2003; 82: $238-242$.

18) Lüthy H, Filser F, Loeffel O, Schumacher M, Gauckler LJ, Hammerle CH. Strength and reliability of four-unit allceramic posterior bridges. Dent Mater 2005; 21: 930-937.

19) Theodorakopoulou LP, Sadowsky PL, Jacobson A, Lacefield WJ. Evaluation of the debonding characteristics of 2 ceramic brackets: an in vitro study. Am J Orthod Dentfacial Orhop 2004; 125:329-336.

20) Kohal RJ, Wolkewitz M, Mueller C. Alumina-reinforced zirconia implants: survival rate and fracture strength in a masticatory simulation trial. Clin Oral Implants Res 2010; 21: 1345-1352.

21) Gomes AL, Montero J. Zirconia implant abutments: a review. Med Oral Patol Oral Cir Bucal 2011; 16:50-55.

22) Curtis AR, Wright AJ, Fleming GJ. The influence of surface modification techniques on the performance of a Y-TZP dental ceramic. J Dent 2006; 34: 195-206.

23) Piconi C, Burger W, Richter H.G, Cittadini A, Maccauro G, Covacci V, Bruzzese N, Ricci GA, Marmo E. Y-TZP ceramics for artificial joint replacements. Biomaterials 1998; 19: 14891494.

24) Kawai Y, Uo M, Wang Y, Kono S, Ohnuki S, Watari F. Phase transformation of zirconia ceramics by hydrothermal degradation. Dent Mater J 2011; 30: 286-292.

25) Fischer J, Stawarczyk B. Compatibility of machined Ce-TZP/ $\mathrm{Al}_{2} \mathrm{O}_{3}$ nanocomposite and a veneering ceramic. Dent Mater 
2007; 23: 1500-1505.

26) Sato H, Yamada K, Pezzotti G, Nawa M, Ban S. Mechanical properties of dental zirconia ceramics changed with sandblasting and heat treatment. Dent Mater J 2008; 27: 408-414.

27) Tanaka K, Tamura J, Kawanabe K, Nawa M, Uchida M, Kokubo T, Nakamura T. Phase stability after aging and its influence on pin-on-disk wear properties of $\mathrm{Ce}-\mathrm{TZP} / \mathrm{Al}_{2} \mathrm{O}_{3}$ nanocomposite and conventional Y-TZP. J Biomed Mater Res A 2003; 67: 200-207.

28) Nakamura T, Nishida H, Sekino T, Nawa M, Wakabayashi K, Kinuta S, Motobe Y, Yatani H. Electrophoretic deposition behavior of ceria/stabilized zirconia-alumina powder. Dent Mater J 2007; 26: 623-627.

29) An HS, Park JM, Park EJ. Evaluation of shear bond strengths of gingiva-colored composite resin to porcelain, metal and zirconia substrates. J Adv Prosthodont 2011; 3: 166-171.

30) Fischer J, Grohmann P, Stawarczyk B. Effect of zirconia surface treatments on the shear strength of zirconia/veneering ceramic composites. Dent Mater J 2008; 27: 448-454.

31) Fischer J, Grohmann P, Stawarczyk B. Sailer I, Hämmerle C. Shear bond strength between veneering ceramics and ceriastabilized zirconia/alumina. J Prosthet Dent 2010; 103: $267-$ 274.

32) Saito A, Komine F, Blatz MB, Matsumura H. A comparison of bond strength of layered veneering porcelains to zirconia and metal. J Prosthet Dent 2010; 104: 247-257.

33) Benetti P, Bona AD, Kelly JR. Evaluation of thermal compatibility between core and veneer dental ceramics using shear bond strength test and contact angle measurement. Dent Mater 2010; 26: 743-750.

34) Fushiki R, Komine F, Blatz MB, Koizuka M, Taguchi K, Matsumura $\mathrm{H}$. Shear bond strength between an indirect composite layering material and feldspathic porcelain-coated zirconia ceramics. Clin Oral Invest 2011; 15: 641-649.

35) Kim HJ, Lim HP, Park YL, Vang MS. Effect of zirconia surface treatments on the shear bond strength of veneering ceramic. J Prosthet Dent 2011; 105: 315-322.

36) Janda R, Roulet JF, Wulf M, Tiller HJ. A new adhesive technology for all-ceramics. Dent Mater 2003; 19: 567-573.

37) Özcan M, Valandro LF. Fracture strength of endodonticallytreated teeth restored with post and cores and composite cores only. Oper Dent 2009; 34: 429-436.

38) Özcan M, Nijhuis H, Valandro LF. Effect of various surface conditioning methods on the adhesion of dual-cure resin cement with MDP functional monomer to zirconia after thermal aging. Dent Mater J 2008; 27: 99-104.

39) Vojvodic D, Predanic-Gasparac H, Brkic H, Celebic A. The bond strength of polymers and metal surfaces using the 'silicoater' technique. J Oral Rehabil 1995; 22: 493-499. 